Review article

\title{
WORK ABSENTEEISM MANAGEMENT IN PROJECT-ORIENTED ORGANIZATIONS
}

\author{
Anđela Lipovac
}

\begin{abstract}
University of Belgrade, Faculty of Organizational Sciences, Belgrade, Serbia
\end{abstract}

Received: 27 November 2020 Revised: 10 December 2020 Accepted: 23 December 2020

\begin{abstract}
Absenteeism is absence from work for both justified and unjustified reasons, a disruptive phenomenon for business whose trend is constantly and steadily growing. The causes can be various, such as family problems, health problems etc. In project-oriented organizations, project team members are more likely to experience extremely high levels of job stress which eventually leads to absenteeism. Consequently, projects can be stopped or delayed if a vital task was dependent on the inputs of the absent person. The economic costs associated with absenteeism are high and significantly affect an organization's profits. Absenteeism management is one of the most important strategic human resource management actions that a project-oriented organization can implement in order to ensure performance and success. This paper aims to systematically review the literature to explain absenteeism in more detail, as well as to present some of the strategies for managing absenteeism.
\end{abstract}

Keywords: Absenteeism, management, project-oriented organizations, strategies.

\section{INTRODUCTION}

The word absenteeism comes from the Latin word absens, which means to be absent from the place to which someone really belongs. Considering that this is a common problem in any organization and complex phenomenon influenced by various, interrelated factors, it can be said that absenteeism is one of the most researched phenomena in the history of human resources and organizational behavior (Patton, 2012).

Despite constant efforts to develop interventions, absenteeism remains an organizational problem for which managers seek a solution. Absenteeism is a phenomenon when an employee or a group of employees is absent from work continuously for a long period of time, or more than once during a short period of time for various reasons (Gangai, 2014). Despite the fact that employers expect workers to be absent from work a certain number of working days each year, excessive absence is equated with reduced productivity and undoubtedly has a major impact on strategies, company finances, morale and other factors (Cucchiella, 2014). Managers consider absenteeism to be a potentially significant cost and often measure productivity costs relative to absenteeism levels (Bankert, 2015). If the analysis of the project-oriented organization reveals that absenteeism has reached a significant level, certain procedures must be implemented in order to reduce this phenomenon, i.e. managers should dedicate themselves to examining the factors that lead employees to be absent from work (Gosselin, 2013).

\section{AIM OF THE PAPER}

For many companies, absenteeism is one of the stubborn and persistent problems for which

Corresponding author. Email: lipovac.andjela@gmail.com

ISSN 2560-4961 (online)

Copyright $(\mathcal{C}$ 2020, The Authors. Published by IPMA Serbia.

This is an open access article under the CC BY-NC 4.0 license (https://creativecommons.org/licenses/bync/4.0/)

Doi: $10.18485 /$ epmj.2020.10.2.4 
there is no clear cause or easy solutions (Thirulogasundaram, 2014). Project-oriented organizations are usually complex and uncertain and therefore project team members are experiencing extremely high level of job stress which leads to absenteeism without exception (Ding et al., 2017). Work in projectoriented organizations is fluid, flexible, reactive and for many employees interesting. However, those characteristics are in positive correlation with pressure which has dangerously damaging effect on increasing absenteeism levels (Asquin et al., 2010). Absenteeism is a behavior that organizations can never eliminate, but they can manage and control. Precisely because of the costs, absenteeism in the industry is more dangerous for its economy than any other factor (Pothuraju, 2019). Only half of employers have a system to monitor this phenomenon, and even fewer have the tools to reduce this phenomenon after its discovery (Kocakulah, 2016). Absenteeism management is one of the most important strategic actions of human resource management that an organization can implement in order to ensure the performance and success of the company, so the aim of this paper is to understand absenteeism and propose strategies that managers can use to reduce this phenomenon in the organization by reviewing the literature. The individual goals of this paper include: a) defining absenteeism as well as the causes and factors that affect it; b) considering the effects of absenteeism on the organization; c) proposal and discussion of absenteeism management strategies.

\section{FINDINGS}

\subsection{Definitions and types of absenteeism}

Voluntary, unjustified absenteeism is when an employee consciously decides to be absent from work (Gangai, 2014). In contrast, unwilling, justified absenteeism is when an employee is really unable to appear at work for objective reasons (Tenhiälä, 2013). According to other authors, absenteeism does not include occasional absence for justifiable reasons beyond control, such as accidents and illness, but is viewed solely as a common pattern of avoidance of duty and/or obligation. (Thirulogasundaram, 2014). Absenteeism can also be seen as a normal absence from work for one or more days, which is often justified by a doctor, but actually occurs due to personal interests and a bad sense of duty. (Cucchiella, 2014). There is agreement in the literature on a general definition of absenteeism according to which it represents a lack of physical presence in a behavioural environment when and where one is expected to be (Gosselin, 2013).

Absenteeism can take the following forms: paid leave - vacation, day off, strike, sick leave, work suspension, leave due to injury at work, abuse of sick leave, disregard for minimum working hours and lack of accuracy, mental leave without physical leave (Cucchiella, 2014). Some authors include in absenteeism leave due to military service as well as educational leave (Pothuraju, 2019).

\subsection{Causes of absenteeism}

Absenteeism cannot be seen as a simple phenomenon because it is associated with many causes and is a symptom of social, economic and, above all, organizational inefficiency (Cucchiella, 2014). It is very important that managers are aware of all the causes of absenteeism so that they can look at the whole situation and conduct a detailed case analysis as well as create a better management policy (Pothuraju, 2019).

\subsubsection{Workplace stress}

Some of the stressors in the workplace are: long shifts, worries about job security, monotony, overwork, feeling disconnected from work and/or colleagues and/or organization, abuse by superiors and/or colleagues, etc. The end result can be a job burn out when an employee feels exhausted, dissatisfied, pessimistic and has a very low level of resistance to disease. Project managers are particularly susceptible to burnout. Behaviours such as being late for work, taking longer breaks than expected, leaving the job earlier, etc. can often be noticed in behaviour. Stress can lead an employee to look for another job which exposes the employer to costs. Before the notice, the employee is absent from the job in order to go for interviews for a new job, and after the notice, the employer is exposed to costs in terms of hiring and training a new employee. Also, until a new person is hired, other employees are exposed to a higher level of stress, who in that period take over the 
responsibilities of the colleague who resigned (Jugdev et al., 2018; Kocakulah, 2016).

\subsubsection{Health issues}

Sickness-related absenteeism refers exclusively to absences due to the health condition of workers. It is often called involuntary absenteeism because it stems from physical/mental incapacity for work, not from unwillingness (Xua, 2012). Despite that, employees refer to health problems even when the threat to health is not actually the real cause of a certain absence. It is also common for employees to be absent from work even due to minor pain (Kocakulah, 2016). Absences caused by poor physical or mental health are alarming due to the increase in the prevalence of chronic diseases in the total population whose large subset is the working population (Bankert, 2015).

\subsubsection{Personal needs}

In order to maintain mental and physical health, some employees go for regular medical examinations, but despite the fact that medical offices have become more flexible in terms of working hours, workers still face the problem of not being able to organize medical examinations in their free time (Kocakulah, 2016).

\subsubsection{Low level of motivation and job dissatisfaction}

Job satisfaction and motivation are closely related, and research shows that there is a negative correlation between job satisfaction and the degree of absenteeism. There are intrinsic and extrinsic factors that affect job satisfaction, with extrinsic factors such as salary, promotion, working conditions, colleagues, supervision and honesty having more significant impact (Thirulogasundaram, 2014).

\subsubsection{Family problems}

Most employees who have children manage to organize who will take care of them during working hours (e.g. private or state nurseries and kindergartens). Nevertheless, it can happen that employee is being forced to leave work to take care of his/her child (Kocakulah, 2016).
Other scenarios can be the cause of this phenomenon, such as the pandemic situation with the covid-19 virus, where the doors of all childcare institutions were closed for a certain period of time.

Family problems also include keeping and fulfilling obligations around the elderly. A large percentage of people do not consider for the option sending their parents to a nursing home, and even when this is not the case, absences from work are often necessary for employees to take their parents for a medical examination or in emergencies that require hospitalization.

This category also may include for example divorce lawsuits that require the presence of an employee in court and/or law office which requires a certain period of absence from work (Kocakulah, 2016).

\subsection{Factors influencing absenteeism}

Variables that affect employees, and are related to absence from work, may be related to individual characteristics (gender, age, level of education, health status, etc.) while others are related to contractual and institutional aspects (amount of sick pay, degree employee protection, company size, type of job, labour market conditions, etc.) If the employee's personal ownership increases due to a certain profit or inheritance, it is to be expected that in the future he will pay less attention to her/his job (Cucchiella, 2014). Employees who have two or more children are no more absent from employees who do not have any children. As the employee's age increases, the duration of leave increases (Bierla, 2013), and younger employees are more often absent than older ones (Redman, 2011).

The group of factors related to culture inside and outside the organization and the hierarchical level includes a sense of responsibility, the degree of motivation and other aspects (Cucchiella, 2014). Through studies, a positive correlation was observed between the degree of absenteeism in managers and the degree of absenteeism in the team they lead. The low degree of absenteeism among managers is explained by the high degree of responsibility they bear, in other words it has been shown that the hierarchical level and 
absenteeism are negatively correlated (Bierla, 2013).

Many papers have investigated the link between dismissal costs and the occurrence of absenteeism in an organization, concluding that fixed-term employees show a much lower degree of absenteeism compared to indefiniteterm workers (Cucchiella, 2014). In general, it can be said that the degree of absenteeism is reduced in situations in which job insecurity is expressed (Bierla, 2013).

There is a positive correlation between the size of the organization and the degree of absence, which can be explained by the fact that the costs of monitoring attendance in large companies are significantly high, so it often happens that the monitoring system is not established, resulting in uncontrolled absenteeism. There is a negative correlation between the unemployment rate and absenteeism (Cucchiella, 2014).

Employees were found to be more absent in countries with higher sick pay (Cucchiella, 2014). Leave can be quite expensive for employees because there is a significant difference between the full salary and the salary received during sick leave, so the financial costs of leave and the degree of absenteeism are negatively correlated (Bierla, 2013).

\subsection{Effects of absenteeism on the organization}

The consequences of absenteeism include direct and indirect costs to the organization (Dale-Olsen, 2014). Direct costs relate to the payment of fixed wages to absent workers and the costs of overtime. Indirect costs include negative effects on the quality of services offered, costs caused by lost productive time of colleagues and supervisors (Nunes, 2017). When hiring a replacement workforce, administrative costs increase as it is necessary to maintain the selection and training of new members. Also, absenteeism can create positive and negative consequences for the individual, colleagues, working group, organization, community and society (Cucchiella, 2014). Some authors divide the costs caused by absenteeism into three categories (Evans, 2002):
1. Direct costs (salaries, bonuses, overtime, business cars, insurance, etc.);

2. Indirect costs (costs of internal replacement workers, costs of external replacement workers);

3. Management costs (costs of the line manager for organizing replacements, conducting interviews after returning to work, monitoring of substitute workers, costs of the HR sector in monitoring absenteeism and training of line managers, etc.).

The effects of absenteeism on the organization create a vicious circle. Projects can be stopped or delayed if a vital task was dependent on the inputs of the absent person, and remaining coworkers can be consequently work overloaded, creating a tense environment and bad mood among colleagues, which results in reduced work quality. Eventually, the mentioned colleagues will also decide to start being absent from work due to the stress they are experiencing due to work overload. Inexperience of reserve staff can disrupt work processes (Saruan, 2019).

\subsection{Absenteeism management}

Kocakulah and associates suggest the next steps in the absenteeism management process (Kocakulah, 2016): a) collecting data in a form suitable for interpretation; b) determining the cause of absenteeism; c) measuring absenteeism; d) strategy proposals, strategy selection, planning, implementation and control of the adopted strategy.

\subsubsection{Strategy suggestions 3.5.1.1 Employee engagement}

Employee engagement is a topic of organizational behavior in which managers examine the degree of employee commitment to the organization and its goals (Anitha, 2014). According to Albrecht and associates, hired employees adopt behaviors that discourage absenteeism (Albrecht, 2015). Engaged employees lead to positive outcomes for the organization such as: increased loyalty, reduced absenteeism, increased productivity, reduced turnover in the organization, increased profitability (Zhang, 2014). The proposed strategies are (McManus, 2015): 


\section{A. Building a trust culture}

Studies show that the level of trust between employees and managers is not satisfactory, which is not surprising if the dismissal rate of workers is taken into account. Nevertheless, trust can still be gained through efforts. The most important thing is that communication is always honest and two-way. In order to achieve effective communication, forums can be created that allow employees to ask questions and receive feedback from managers. In this way, the spread of rumors and mistrust among employees is significantly reduced, and at the same time the management gets the opportunity to understand the needs of employees. The best way to show trust is to delegate responsibilities with the necessary authority.

\section{B. Building a perception of honesty/justice}

Honesty is essential for the development of trust and psychological security, and consequently leads to increased employee engagement. The distribution of responsibilities and results must be fair, decisions must be made impartially and according to clearly defined criteria. Reslocation of resources, necessary reduction of the number of employees and assignment of additional work responsibilities must be carried out in a way that the entire organization perceives as fair, and it is necessary to include employees in the decision-making process. Also, dismissal decisions should always be announced earlier to reduce feelings of insecurity and increase a sense of honesty.

\section{Building employee recognition and reward programs}

Employees must have a belief that their work is considered significant, so they should be recognized and rewarded for a job well done. The recognition and reward program requires a high commitment of management and must not have any indications of favoritism. While some employees may crave recognition, others may want additional responsibilities, more flexible working hours, promotion etc. Rewards should be created for each employee individually, which is why the prerequisite is that management must be familiar with the factors that meet the specific needs of employees.

\section{Setting challenging but also achievable goals}

Managers need to set both high and achievable goals. In order for employees to be motivated to meet their goals, it must be clearly explained to them what is expected of them and what their role and purpose is within the entire organization and how they contribute to it.

\section{E. Development of knowledge and skills of employees through trainings}

When employees are provided with training in order to develop knowledge and skills, their self-confidence increases and their fear of insecurity at work decreases. Trainings motivate employees by assuring them that there is a desire to reach their full potential.

\subsubsection{Leadership style}

In the process of managing absenteeism, managers have many determinants out of control (e.g. employment level), some are partially under their control (e.g. opportunities for promotion), and some are completely under their control, such as leadership style. It has been proven that the use of transformational management style raises the level of job satisfaction, which in turn reduces the level of absenteeism (Frooman, 2012).

\subsubsection{Communication strategy and motivation}

The importance of effective communication is invaluable because everything managers do involves communication (Filipović, 2012). Managers who promote communication relationships create a general pattern within the organization that supports employee engagement (Hossain, 2013). Since communication can modify resource behavior, its importance in identifying this phenomenon in the organization is clear. Also, it is very important to talk to all employees in order to get them familiar with all the rules and procedures regarding absenteeism. After returning to work, especially in cases of long absences, communication ensures that new needs of the employee are established if they exist and that they are provided with the necessary psychological support and thus 
reduce the degree of potential absences in the future. (Cucchiella, 2014).

According to hedonistic theories of absenteeism, the main reason for being absent from work is to avoid a painful and unsatisfactory situation at work (Thirulogasundaram, 2014). According to motivational hygiene theory, in order to increase job satisfaction and thus reduce absenteeism levels, hygiene factors that include organizational policy, oversight system, employee-manager relationship, employee salaries and safety issues, as well as motivational factors that include task delegation, reward clarity of tasks, etc. should be influenced (Saruan, 2019).

\subsubsection{Initiatives to improve the health of employees}

Employees who have health problems are often less productive at work or absent from it. For some companies, the costs of reduced productivity may outweigh the costs of direct medical care (Mitchell, 2013).

Health promotion can enable the quality and productivity of an organization in the long run. Health promotion programs usually provide services that educate people about their health and treatment needs. In the work of Mitchell R. et al. health promotion services included one or more telephone conversations with health professionals about the need for quality ways to treat certain health problems. The programs contained information on preventive measures, symptoms, as well as more favorable alternatives for treatment. The goal of the program was to provide employees with the information and necessary tools to improve their health and reduce medical costs, which in turn leads to increased productivity at work. The study proved that investing in a healthy workforce can increase employee productivity (Mitchell, 2013). Health promotion can include interventions and programs to reduce stress, increase physical activity, reduce high blood pressure and cholesterol, reduce excess weight, reduce consumption of alcohol, tobacco etc. In some cases, programs include cancer screening, free flu vaccination for at-risk employees etc. (Cucchiella, 2014).
Employees tend to reduce the financial risk associated with illness and can achieve significantly lower premiums if health insurance goes through the employer due to economies of scale in group purchases. On the other hand, employers have an interest in providing health insurance because in this way they attract quality employees to their organization and reduce costs caused by high turnover (Xua, 2012). An employer's concern for the health of its employees can be expressed through the provision of private health insurance.

Employee Assistance Program - EAP is important instrument of employee assistance in relation to behavioral health problems, personal problems and work-related problems that cause absences (Nunes, 2017). Through various types of information, counseling, education, and evaluation services, EAP helps individuals and organizations address productivity-related issues, such as health, family, financial, and emotional issues, relationships and justice at work, bullying, stress, etc. Associations such as the Employee Assistance Professionals Association (EAPA) and the European Employee Assistance Forum The Employee Assistance European Forum EAEF offer various types of employee assistance and accredited training programs for professionals who provide assistance to employees, set standards and use protocols to monitor the performance of services. EAP offers individual counseling that supports employees to identify effective confrotation strategies for personal and professional stressors with a high degree of confidentiality. The EAP work system is often made up of social workers, psychologists, psychotherapists and substance abuse experts. It uses strategies and treatments such as cognitive behavioral therapy, motivational conversations, and stress management to help employees find a new source of energy related to problems in the workplace, family, child or elderly care, depression, anxiety, and substance abuse. Unlike other behavioral health services, EAP professionals and employees work together with the ultimate goal of restoring work functions to employees. Organizations may outsource employee assistance programs or may have in-house EAP staff. A study by Nunes et al showed that the level of absenteeism was significantly reduced among 
users of EAP services compared to employees who are not users of these services. It was also concluded that EAP services are effective in reducing the degree of absenteeism among the working population suffering from mild to moderate problems (Nunes, 2017).

\subsubsection{Interview after returning to work and records of arrivals}

After the employee informs superior that he/she will be absent, the manager should enter the data into the database that serves to monitor the occurrence of absenteeism. The database should always be updated and provide information such as the date of absence, the nature of the illness, the reason for absence, the expected date of return to work, remittances from doctors if available, etc. The manager should be in continuous contact with the employee in case of a longer absence in order to show care for him/her as well as the necessity to return to work. After the employee returns to work, it is necessary to conduct an interview on absence on the same day. The interview aims to make the employee feel the commitment of the organization in terms of control of absenteeism in the workplace. During the conversation, there is a possibility to detect various personal or business problems that can potentially be solved with the support of managers and which are the background but the real cause of absence. (Evans, 2002) Records of arrivals are also a very important tool, especially for workers who show absenteeism through frequently being late for work or early getting out from work (Deery, 2014).

\subsubsection{Programs for balancing private and business life}

It is believed that the lack of balance between private and business life is the cause of poor mental and physical condition and lack of mental well-being. Companies that actively promote the policy of balancing private and business life experience a higher level of employee performance and have a lower degree of absenteeism caused by disease (Zheng, 2015). Increased engagement, level of job satisfaction and company profitability were also noticed (Mohd, 2016).
The existing literature includes five groups of organizational programs for establishing a balance between private and business life: a) flexible work arrangements; b) health-oriented programs; c) the provision of childcare benefits or services; d) allowing leave as needed to meet family obligations; e) organizational understanding and support (Zheng, 2015). Flexible work arrangements refer to flexible working hours, part-time work and job sharing. Epstain and co-workers concluded that showing empathy by managers in terms of flexible working hours results in positive outcomes for the organization (Epstein, 2015). Health-oriented programs often cover the provision of healthy meals, gym subscriptions, and other benefits that focus on disease prevention and thus reduce the costs associated with absenteeism and employee turnover. Assistance programs for children can take the form of organized day care/kindergarten (Zheng, 2015).

\subsubsection{Incentives}

A common example of an incentive is for a company to pay a certain amount of money to its employees for each day off they do not take. At the end of the year, employees receive money for vacation days that they did not use. For organizations for which this type of incentive is too expensive, there is an alternative ,perfect presence“ approach. The arrival of employees at work is monitored for a certain period of time. When employees who have a proper history of coming to work are determined, a cash prize winner game is organized. Some of the other incentive programs for employees are: a gift from the organization, organizing a company party, a voucher for buying things in the organization's facilities, etc. Some authors warn that employees should not be rewarded for what they should already be doing, and that is regular attendance at work, but despite this, this type of motivation for employees not to be absent from work is very common in organizations (Kocakulah, 2016).

\section{CONCLUSION}

Absenteeism is a behavior that organizations can never eliminate, but they can manage and control. Absenteeism management is one of the most important strategic human resource 
management actions that a project-oriented organization can implement in order to ensure the performance and success of the company, as well as to prevent huge costs. The responsibility for managing absenteeism often falls on the immediate supervisors, who are often the only ones who have insight that one of the employees is absent. To ensure consistency in managing this phenomenon, supervisors should have adequate training on how to conduct interviews after employees return to work and how to ensure the implementation of disciplinary procedures (Evans, 2002). This paper provides an overview of strategies that can be used in the process of absenteeism management obtained by a systematic literature research. Basically, companies should not have an overly restrictive absenteeism policy that forces employees to come to the office even when they are sick but should accept that a certain level of absenteeism is actually desirable (Pothuraju, 2019). Of the strategies proposed in this paper, the most practical is to start the management process with records (arriving and leaving the job) and interviews after returning to work.

\section{REFERENCES}

Albrecht, S. L. (2015). Employee engagement, human resource management practices and competitive advantage: An integrated approach. Journal of Organizational Effectiveness: People and Performance, 2(1), pp. 7-35.

Anitha, J. (2014). Determinants of employee engagement and their impact on employee performance. International Journal of Productivity and Performance Management, 63, pp. 308-323.

Asquin, A., Garel, G., \& Picq, T. (2010). When project-based management causes distress at work. International Journal of Project Management, 28(2), pp. 166172.

Bankert, B. C. (2015). Regional economic activity and absenteeism: A new approach to estimating the indirect costs of employee productivity loss. Population Health Management, 18(1), pp. 47-53.

Bierla, I. H. (2013). New evidence on absenteeism and presenteeism. The
International Journal of Human Resource Management, 24(7), pp. 15361550.

Cucchiella, F. G. (2014). Managing absenteeism in the workplace: the case of an Italian. Procedia - Social and Behavioral Sciences, 150, pp. 1157 1166.

Dale-Olsen, H. (2014). Sickness absence, sick leave pay, and pay schemes. Review of Labour Economics \& Industrial Relations, 28(1), pp. 40-63.

Deery, S. W. (2014). A moderated mediation analysis of job demands, presenteeism, and absenteeism. Journal of Occupational and Organizational Psychology, 87, pp. 352-369.

Ding, X., Li, Q., Zhang, H., Sheng, Z., \& Wang, Z. (2017). Linking transformational leadership and work outcomes in temporary organizations: A social identity approach. International Journal of Project Management, 35(4), pp. 543-556.

Epstein, S. A. (2015). Managers' familysupportive supervisory behaviors: A multilevel perspective. Organization Management Journal, 12(2), pp. 49-62.

Evans, A. W. (2002). From Absence To Attendance - Second Edition. London: Chartered Institute of Personnel and Development.

Filipović, V. I. (2012). Menadžment $i$ organizacija. Beograd: Fakultet organizacionih nauka.

Frooman, J. M. (2012). Transformational and passive avoidant leadership as determinants of absenteeism. Leadership \& Organization Development Journal, 33(5), pp. 447-463.

Gangai, K. N. (2014). Absenteeism at workplace: What are the factors influencing to it? International Journal of Organizational Behaviour \& Management Perspectives, 3, pp. 12581265.

Gosselin, E. L. (2013). Presenteeism and absenteeism: Differentiated understanding of related phenomena. Journal of Occupational Health Psychology, 18(1), pp. 75-86.

Hossain, L. M. (2013). Communication 
network dynamics during organizational crisis. Journal of Informetrics, 7(1), pp. 16-35.

Jugdev, K., Mathur, G., \& Cook, C. (2018). Linking workplace burnout theories to the project management discipline. International Journal of Managing Projects in Business, 11(7)

Kocakulah, C. M. (2016). Absenteeism Problems And Costs: Causes, Effects And Cures. International Business \& Economics Research Journal, 15(3), pp. 89-96.

McManus, J. M. (2015). Strategies To Build Trust And Improve Employee Engagement. International Journal of Management \& Information Systems, 19(1), pp. 37-42.

Mitchell, J. R. (2013). Improving Employee Productivity Through Improved Health. Journal of Occupational and Environmental Medicine, 55(10), pp. 1142-1148.

Mohd, I. H. (2016). Work-life balance: The effect on absenteeism among employees in a Malaysian utility company. International Journal of Economics and Financial Issues, 6, 154-157.

Nunes, P. A. (2017). The Effect of Employee Assistance Services on Reductions in Employee Absenteeism. Journal of Business and Psychology, pp. 50-62.

Patton, E. J. (2012). Context and the social representation of absenteeism: Absence in the popular press and in academic research. Human Relations, 65, pp. 217240.
Pothuraju, V. S. (2019). Impact of Employee Absenteeism on Logistics Efficiency. SUMEDHA-Journal of Management, $8(4)$, pp. 56-64.

Redman, T. H. (2011). Working Here Makes Me Sick! The Consequences of Sick Building Syndrome. Human Resource Management Journal, 21, pp. 14-27.

Saruan, M. A. (2019). Organisational Intervention on Absenteeism among Workers: A Systematic Review. Jurnal Pengurusan, 57, pp. 1-17.

Tenhiälä, A. L. (2013). Organizational justice, sickness absence and employee age. Journal of Managerial Psychology, 28, pp. 805-825.

Thirulogasundaram, V. P. (2014). Job Satisfaction and Absenteeism interface in Corporate Sector - A study. IOSR Journal Of Humanities And Social Science (IOSR-JHSS), 19(3), Ver. I, pp. 64-68.

Xua, X. J. (2012). Does health insurance reduce illness-related worker absenteeism? Journal of Applied Economics, 44, pp. 4591-4603.

Zhang, T. A. (2014). The relationship between leadership paradigms and employee engagement. Journal of Global Responsibility, 5(1), pp. 4-21.

Zheng, C. M. (2015). Developing individual and organisational work-life balance strategies to improve employee health and wellbeing. Employee Relations, 37(3), pp. 354-379. 